\title{
Impact of a primary school-based nutrition and physical activity intervention on learners in KwaZulu-Natal, South Africa: A pilot study
}

\author{
Rowena Naidoo (M Sports Science) ${ }^{1}$ \\ Yoga Coopoo (D Phil, FACSM) ${ }^{2}$ \\ Estelle V Lambert (BA, MS, PhD (Physiology)) $)^{3}$ \\ Catherine Draper (BSocSci (Hons), MA (Psychology), PhD) ${ }^{3}$ \\ 1 Department of Life Orientation, Faculty of Education, University of KwaZulu-Natal \\ 2 Centre for Exercise Science \& Sports Medicine, Faculty of Health Sciences, University of the Witwatersrand \\ 3 MRC/UCT Research Unit of Exercise Science and Sports Medicine, Department of Human Biology, University of Cape Town
}

\begin{abstract}
Background. The opportunity for children to be physically active during school hours is rapidly decreasing in selected schools. This study evaluated the effects of a nutrition and physical activity (NAP) intervention incorporated within the school curriculum.

Study design and methods. A prospective empirical pilot study with an intervention and an assessment of pre- and post-intervention fitness. Learners completed a NAP questionnaire and participated in a battery of fitness tests before and after intervention.

Setting. A purposive sample of four primary schools in KwaZuluNatal was selected by the provincial Department of Health.

Interventions. The NAP intervention was designed to introduce various methods of physical activity and healthy nutritional habits within the school's existing curriculum. Classroom-based intervention materials were developed to provide cost-effective and, more importantly, a sustainable intervention.

Results. Post-intervention results showed a significant increase $(p<0.05)$ in the average number of sports participated in by each learner during physical education/life orientation periods. Learners were motivated to participate in physical activity including games and sports during break times. A general increase in afterschool activities from pre- to post-intervention per learner was noted.

Conclusion. A school-based physical activity and nutrition intervention programme has the potential to increase the physical activity of learners and to a lesser degree their nutritional behaviour.
\end{abstract}

\section{CORRESPONDENCE:}

\section{Rowena Naidoo}

University of KwaZulu-Natal

Edgewood Campus

Private Bag X03

Ashwood, 3605

Tel/fax: (031) $2603676 / 2603595$

E-mail: naidoor3@ukzn.ac.za

\section{Introduction}

The global prevalence of chronic, non-communicable diseases (NCD) is on the rise, with developing countries experiencing the greatest burden, and in which cardiovascular disease is already the leading cause of mortality. ${ }^{1}$ Similarly, the number of persons with diabetes is projected to double between 2000 and 2030, with over $80 \%$ or 300 million from developing countries. This increase in the prevalence of chronic diseases in the developing world has been attributed to changes in lifestyle associated with development and urban migration, including obesity, unhealthy diet, smoking and physical inactivity. ${ }^{2}$ The urgent need to address these risk factors in both developed and developing countries is reflected in the World Health Organization Global Strategy on Diet and Physical Activity for Health. ${ }^{3}$

Importantly, these risk behaviours track from childhood, with body mass index (BMI) levels in childhood strongly predictive of adult obesity. ${ }^{4}$ In the Bogalusa Heart Study overweight children (BMI>95th centile) at 2 - 5 years were found to be 4 times as likely to become overweight adults. ${ }^{5}$ South Africa is a country of paradox, where obesity in children co-exists with stunting and early nutritional deprivation. For example, in primary school children $22 \%$ of girls and $17 \%$ of boys are overweight or obese. ${ }^{6}$ In children under the age of 9 years, overweight and stunting are equally prevalent, and risk of obesity in stunted children is nearly twofold higher, with potentially long-term negative health consequences. ${ }^{7}$

South African children also demonstrate unhealthy eating habits with school tuck-shop choices favouring cooldrinks, chips, cheese curls and fried cakes $(70 \%)$, and urban primary school learners report eating fruit or vegetables less than 3 times per week. ${ }^{8}$ Of concern is that many schools rely on income generated from these tuck-shops for supplemental income and informal vendors, who typically sell foods of low nutritional value, high in fats and sugars, are also very common.

Similarly, recent studies suggest that $40 \%$ of children and youth are getting little or no moderate to vigorous activity each week. ${ }^{9}$ With only just over half of high school learners reporting regularly scheduled physical education classes, less than $60 \%$ of these engage in vigorous activity during the actual classes, and in fact, over $30 \%$ do not participate. ${ }^{9}$ In primary school learners, engagement in physical education classes is even lower than in high school. ${ }^{9}$ 
Schools are an established setting for health-promotion activity, and in this setting may influence health-related beliefs and behaviours early in life before they are established as adult patterns. ${ }^{10}$ An additional potential benefit is that by improving the health of school children, educational performance and learning may be enhanced. ${ }^{11}$

Patterns of physical activity acquired during childhood and adolescence are more likely to be maintained throughout one's life span, thus providing the basis for active and healthy ageing. ${ }^{12,13}$ Therefore, school-based physical activity interventions are advantageous since programmes can become institutionalised into the regular school curriculum, staff development and other infrastructures. ${ }^{14}$

International groups recommend that children should participate in at least 30 minutes of moderate to vigorous physical activity on most days, ${ }^{12}$ although other consensus panels have recommended one $^{15,16}$ or more ${ }^{17}$ hours of physical activity per day for children. A basic function of physical education is to engage learners in moderate to vigorous physical activity, a requirement for experiencing both health and motor skill development benefits. ${ }^{18}$ By providing opportunities for physical activity, quality physical education can make important contributions to public health. ${ }^{19}$

In addition to health and fitness benefits achieved through nutrition and physical activity interventions, studies have demonstrated the relationship between physical activity and academic performance. ${ }^{20-22}$ The addition of physical education to the curriculum has resulted in small positive gains in academic performance. Quasi-experimental data also suggest that allocating more curricular time to programmes of physical activity does not negatively affect academic achievement, even when time allocated to other subjects is reduced. ${ }^{23}$ Physical activity has been shown to demonstrate positive influences on concentration and memory ${ }^{24}$ and on classroom behaviour. ${ }^{23}$

In a recent review of successful school-based nutrition and physical activity interventions, the following common factors were present: incorporation of a nutrition-based curriculum by trained teachers, a physical activity programme/component, a parental/ family component, a food service or tuck-shop intervention, and with the intervention grounded in a relevant behavioural change theory. ${ }^{25}$

There has been very little research on school-based programmes for the prevention of NCD in developing countries. However, schoolbased health promotion may have a greater impact in these settings, as social networks are often stronger, respect for teachers greater, and NCD risk factors less established among school children than in most developed countries.

The present study implemented a school-based nutrition and physical activity (NAP) intervention which was developed and designed specifically for the individual needs of the school to increase physical activity participation and promote healthy lifestyles among learners. The primary goals of the intervention were to $(a)$ increase the physical activity of learners by implementing a classroom-based physical activity intervention and $(b)$ promote physical activity during lunch-breaks and after school hours. Additionally, the knowledge, attitudes and practices of learners towards physical activity before and after intervention were determined. This paper reports primarily on the physical activity component of the intervention.

\section{METHODS}

\section{Research design}

This study is a prospective empirical pilot study with an intervention and an assessment before and after intervention.

\section{Sample}

A purposive sample of four primary schools in KwaZulu-Natal was selected by the KwaZulu-Natal Department of Health. Schools were selected based on their easy accessibility and close proximity to each other (not more than $50 \mathrm{~km}$ away from each other).

A total sample of 4 principals, 10 educators and 256 learners in Grade 6 agreed to participate in the school-based intervention for a period of 6 months. There were no control schools, as the aim of this study was to examine the feasibility of the intervention and make amendments where applicable before the larger study is implemented. However, each participant served as their own control as there was a pre- and post-testing programme. Permission to conduct the study in selected schools was granted from the KwaZulu-Natal Departments of Health and Education. Ethical clearance from the University of KwaZulu-Natal was granted for this study. Informed consent forms were completed by all participants in the study.

\section{Measuring instruments}

Fieldwork at the schools involved both quantitative and qualitative methods of assessment. Assessments were administered before and after intervention to all schools. Quantitative assessments included the use of a learner questionnaire. The questionnaire aimed to determine the knowledge, attitudes and practices of learners towards physical activity and basic nutrition. Physical activity and sports participation were captured by self-report and reflected the following time periods: club/team level during school hours, during physical education (PE)/life orientation (LO) lesson, and after school.

In addition, learners participated in selected components from the Eurofit ${ }^{26}$ Physical Fitness Test Battery before and after intervention. The test battery included the following components: flexibility (sitand-reach), muscular endurance (30-second sit-ups) and explosive power (standing long jump). Body weight and height were measured without shoes and body mass index (BMI) was calculated $\left(\mathrm{kg} \cdot \mathrm{m}^{-2}\right)$. 'Overweight' and 'obesity' were defined using the age- and sexspecific criteria ${ }^{27}$ used by the Centers for Disease Control and the World Health Organization. ${ }^{28}$ A BMI greater than the 85th percentile is considered 'at risk of overweight' and a BMI greater than the 95th percentile is considered 'obese'.

All assessment tools were developed in conjunction with the University of Cape Town and were also used among learners in rural communities in Limpopo and in Alexandra Township in Gauteng. Minor adjustments were made to the questionnaire to accommodate the language of the learners from KwaZulu-Natal.

Qualitative assessments included observation of learners' physical activity and sports participation during lunch breaks; semi-structured interviews with the principals and selected Grade 6 educators were conducted by the researchers before and after intervention.

\section{Measures}

Measures were conducted at the schools, during class hours and under direct supervision from researchers, educators, and school- 


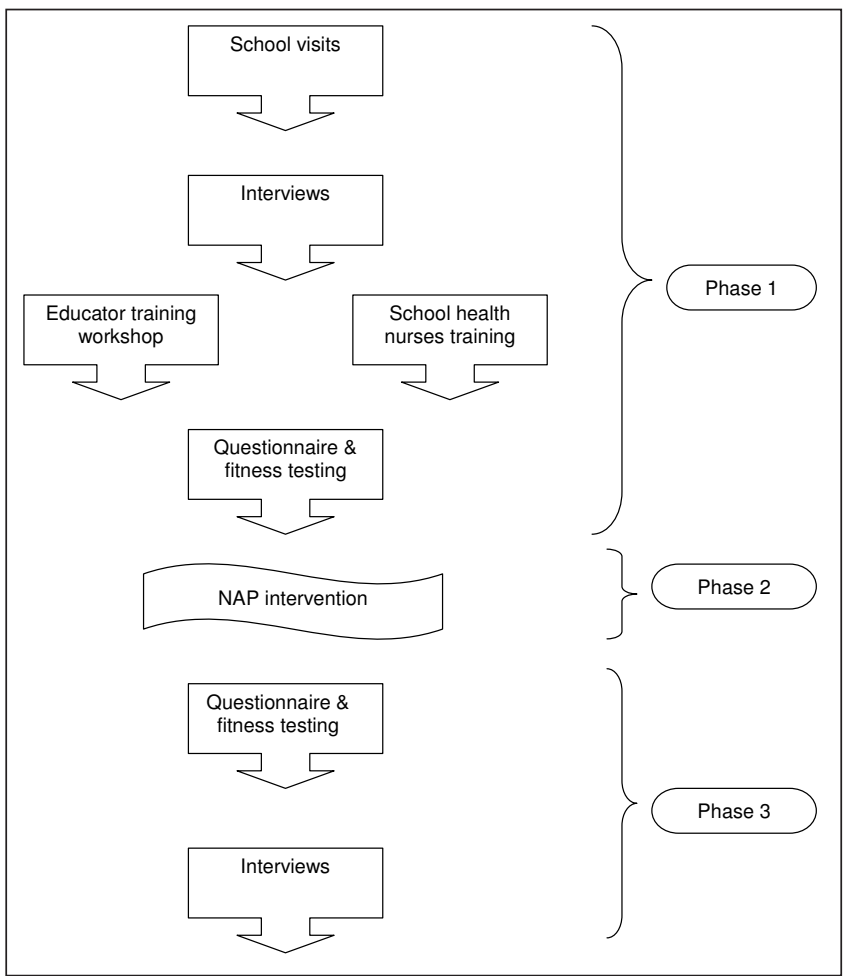

Fig. 1. Phases of the study.

health nurses. All field workers were trained over a 2-week period in order to maintain consistency and reliability of testing.

\section{Phases of the study (Fig. 1)}

Phase 1. This involved initial school visits by the researchers to brief the school principals and educators about the study. Thereafter, interviews with principals and educators regarding their knowledge and attitudes towards physical activity and teaching methodologies of physical activity were investigated. Selected educators attended training workshops on learning and implementation of the NAP intervention. Short courses on learners' health, physical activity and nutrition were included. Subsequent training of provincial school health nurses to assist in questionnaire administration, fitness testing and data collection was conducted by the researchers.

Phase 2. Two weeks before the NAP intervention was implemented by trained educators, questionnaires and fitness tests were administered to learners. The intervention was monitored by the research team for a 6-month period.

Phase 3. Questionnaires were redistributed to learners and physical fitness was reassessed. Principals and educators were interviewed by the researchers to gain feedback regarding the intervention regarding strengths, weaknesses, challenges and recommendations.

\section{Intervention}

The NAP intervention was designed to introduce various methods of physical activity and healthy nutritional habits within the school's existing curriculum. Classroom-based intervention materials were developed to provide cost-effective and, more importantly, a sustainable intervention. The key strategy was to integrate the NAP intervention into the school curriculum by means of an inter-learning areas approach via trained educators. Educators were trained to lead intervention activities, were provided with copies of all the activities and were allowed to choose which activity and, when necessary, to include such activities within particular lessons. The intervention was designed to be implemented by the school personnel with minimal external support to enable implementation after the study to be practicable and realistic.

\section{Curriculum training workshops}

The research team conducted workshops for school educators on a voluntary basis. A 3-hour session before and during the pilot study and at least 2 monthly follow-up visits to schools by the research team was provided.

Grade-appropriate learning materials were designed and developed to incorporate nutrition and physical activity into selected learning areas, namely English, mathematics, natural science, social science and life orientation. Workshops were 'hands on' with educators actively engaging in practical sessions. At the end of the session educators were given booklets containing classroom-based physical activities. Educators were encouraged to promote physical activity outside the class, specifically during lunch breaks.

\section{Nutrition}

Schools were to increase the availability of healthy products (market low-fat food, fruit, juices and water) and decrease the availability of unhealthy products (fizzy drinks, selected sweets and chips) at all school tuck-shops if applicable. Educators were to advise and prompt learners to purchase healthier food and drinks from school tuck-shops. Learners were also provided with water bottles.

\section{School policies}

The intervention aimed to establish a health-promoting environment in the schools through physically active and healthy learners, educators and principals. School staff and learners also engaged in policy change efforts, such as developing a nutrition policy banning fizzy drinks in school.

\section{Statistical methods}

A sub-sample of 185 questionnaires and fitness tests was analysed. Data were missing for 71 learners due to learners not attending the post-intervention measures, inadequately filling out questionnaires or no longer attending the school. The data were analysed by the Statistical Package for the Social Sciences (SPSS) Version 15. Descriptive (means and standard deviations), and interferential (paired $t$-tests and chi-square tests of independence) statistics were used to test significant differences before and after intervention. A level of significance of $p<0.05$ was used for all interferential analyses. Interviews were coded for content in order to determine common themes.

\section{Results}

\section{Demographics of the learners}

The demographic data of all the learners are shown in Table I. Although $83 \%$ of learners live in brick homes and the majority have essential electrical appliances, it should be noted that an average of 6 individuals reside in a 4-roomed house. Households varied from 2 to 20 occupants. Therefore one can assume that the socio-economic status of the majority of learners in this study ranges from low- to middle-income groups. About $69 \%$ of learners travel distances greater than approximately $20 \mathrm{~km}$ to and from their school. Learners' modes of transportation include taxi, bus, train and foot. 
Physical activity and sports participation before and after intervention

Results from the learner questionnaire determined physical activity and sports participation during selected time periods.

\section{Physical activity at club/team level during school hours}

Fig. 2 represents physical activity and sports participation of each learner at club/team level. It is evident that in every case, participation is significantly $(p<0.05)$ greater after intervention than before intervention. The largest increases of $22 \%$ and $17 \%$ were in hockey and netball respectively. These increases were probably due to the fact that the survey was done during the hockey and netball season. Incidentally, a $14 \%$ increase was found in dancing. This increase could be a direct result of the intervention as dance clubs were introduced into selected schools as part of the intervention programme.

\section{Physical activity during physical education/life orienta- tion lessons}

Overall, results showed that after intervention there was a significant increase $(p<0.05)$ in the average number of sports participated in by each learner during physical education/life orientation lessons. Participation had increased considerably in cricket ( 6 - 23\%), hockey (14 - $37 \%$ ) and dancing (6-18\%). This may also be as a result of different sports being offered in physical education/life orientation lessons at different times of the year.

\section{TABLE I. Learner demographics $(N=185)$}

\begin{tabular}{lll}
\hline Demographics & $\mathbf{N}$ & $\mathbf{( \% )}$ \\
Gender & & \\
$\quad$ Males & 81 & 44 \\
$\quad$ Females & 104 & 56 \\
Racial group & & \\
$\quad$ Black & 154 & 83 \\
$\quad$ Coloured & 15 & 8 \\
$\quad$ Indian & 16 & 9 \\
Home language & & \\
$\quad$ Zulu & 142 & 77 \\
$\quad$ English & 31 & 17 \\
$\quad$ Other (Xhosa, Sotho, Afrikaans) & 12 & 6 \\
Primary caregiver & & \\
$\quad$ Mother & 105 & 57 \\
$\quad$ Grandmother & 35 & 19 \\
$\quad$ Other (including brother/sister, aunt) & 45 & 24 \\
$\quad$ Brick home & & \\
$\quad$ Mud homes & 153 & 83 \\
$\quad$ Flats & 17 & 9 \\
Homes consisting of four rooms, & 15 & 8 \\
excluding the bathroom & & \\
Television sets in households & 165 & 89 \\
Radios in households & & \\
Refrigerator in households & 175 & 90 \\
Electric stove with oven in households & 159 & 86 \\
Cook on open fires & 168 & 91 \\
Gas stoves in households & 136 & 74 \\
Paraffin stoves in households & 43 & 22 \\
Grow vegetables or fruit trees \\
Learners attend school in the same \\
neighbourhood in which they live & 43 & 23 \\
$\quad 37$ & 28 \\
& 144 & 78 \\
& 57 & 31 \\
& & \\
\hline
\end{tabular}

Subsequently, the frequency of participation in physical activities in general was that $20 \%$ of learners did exercise 'more than 5 times' per week before intervention, while this figure increased to $43 \%$ after intervention. In addition, the percentage of learners who 'do not participate' had been reduced from $7 \%$ to $2 \%(p<0.05)$ after intervention.

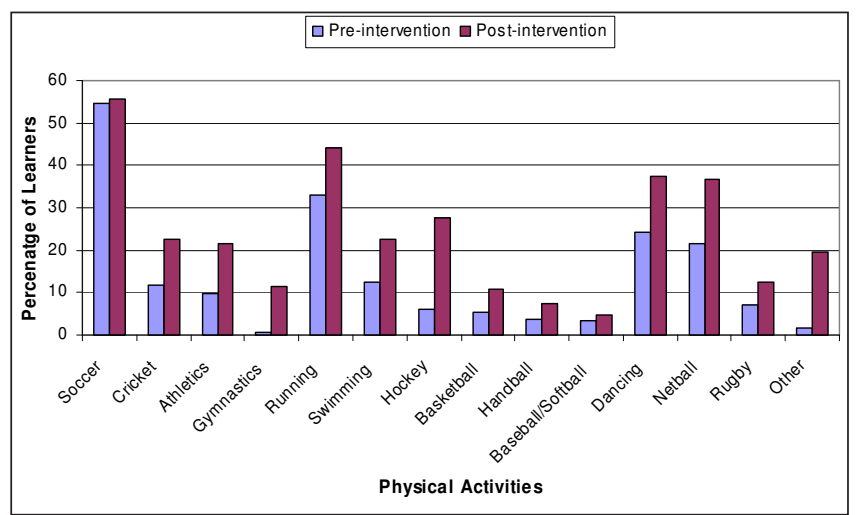

Fig. 2. Participation of activities at club/team level.

\section{Physical activity and sports participation after school}

Fig. 3 shows a general increase in after-school activities from pre- to post-intervention per learner. This could be as a result of the intervention where educators were advised by researchers to stress the importance of regular physical activity during school as well as after school hours. There was a $10 \%$ increase in the number of learners performing chores around the house. Additionally, learners participating in physical activity 'more than 5 times' per week after school had increased significantly $(p<0.05)$ from $35 \%$ to $55 \%$ after intervention.

\section{Physical activity and sports participation during school breaks}

Reports from educators after intervention stated that learners were motivated to particpate in physical activity including games and sports during break times. As part of the intervention, educators supervised and provided learners with necessary equipment for activities. It was also reported by the educators that if physical activity or sports equipment is made readily available for learners during break times, learners' physical activity or sports particiption is increased. Educators reported an overall increase in the enthusiasm and the number of learners who particpated in games and sport during lunch breaks. The Grade 6 learners' enthusiasm created a new culture of games and play among other grades.

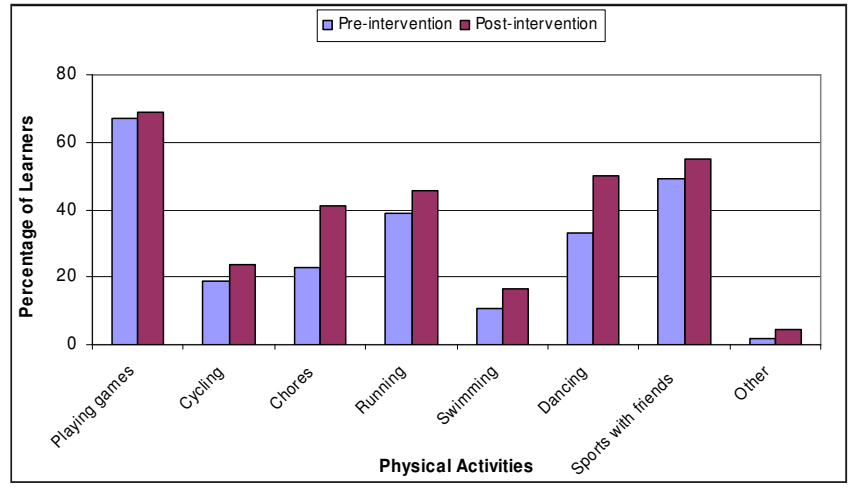

Fig. 3. Participation in activities after school. 
Overall, it was estimated that during the 6 months of the NAP intervention, physical activity among learners ranged from 45 to 215 minutes per week of moderate to vigorous physical activity during school hours. This calculated value reflects an accumulative integration of physical activities across various learning areas/ subjects. Educators kept log books of the frequency, duration and perceived intensity of the learners' physical activity during school hours.

\section{Nutrition}

Initially, the nutrition component of the intervention was not readily accepted by all schools as it was preconceived that change could lead to financial drawbacks. However, schools introduced gradual nutritional changes in tuck-shops and discovered that there were no negative financial implications. Educators reported a greater turnover during the intervention, with healthier food and drink options in selected school tuck-shops.

The researchers observed that healthier food and drink choices were now available in school tuck-shops, such as low-fat yoghurts and fruit. Carbonated drinks were also eliminated from menus and substituted with energy drinks and juices. As part of the intervention, learners were provided with water bottles to encourage the drinking of water throughout the school day. Principals reported that learners were motivated to carry the water bottles and regularly drank water during school hours. The researchers also observed that learners continued to purchase food and drinks as usual from school tuckshops although their original choices were unavailable. These alternatives appeared to be gladly accepted by learners, according to reports from principals and educators.

\section{Fitness tests}

Table II shows the scores of the fitness tests conducted before and after the intervention. There were no significant changes in the flexibility (sit-and-reach) scores. There is an increase from $11 \%$ to $23 \%$ in the '>20' sit-up category and an overall increase in the average number of sit-ups from 16 to 18 . This increase in abdominal muscular endurance is significant $(p<0.05)$ for both boys and girls.

The explosive strength component (standing long jump) has remained unchanged at $1.30 \mathrm{~m}$ for the girls, with a $10 \mathrm{~cm}$ increase for the boys after intervention; this was not significant.

All learners were below the 85th ('at risk of overweight') and 95th percentile ('obese') BMI.

\section{Educator training workshops}

Educators rated the training workshops useful and appropriate to the various learning areas and supported the approach of staff de-

\begin{tabular}{|c|c|c|c|c|}
\hline \multirow[t]{2}{*}{ Components } & \multicolumn{2}{|c|}{ Before intervention } & \multicolumn{2}{|c|}{ After intervention } \\
\hline & Boys & Girls & Boys & Girls \\
\hline $\begin{array}{l}\text { Sit-and-reach } \\
\text { test }(\mathrm{cm})\end{array}$ & $29.11 \pm 6.05$ & $30.73 \pm 6.52$ & $29.38 \pm 6.45$ & $31.62 \pm 6.89$ \\
\hline Sit-ups & $18 \pm 3$ & $15 \pm 4$ & $20 \pm 4$ & $16 \pm 4$ \\
\hline $\begin{array}{l}\text { Standing } \\
\text { broad jump (m) }\end{array}$ & $1.50 \pm 0.21$ & $1.30 \pm 0.17$ & $1.60 \pm 0.211$ & $30 \pm 0.19$ \\
\hline BMI $\left(\mathrm{kg} \cdot \mathrm{m}^{-2}\right)$ & $19.15 \pm 0.52$ & $19.94 \pm 0.37$ & $19.95 \pm 0.63$ & $20.59 \pm 0.38$ \\
\hline
\end{tabular}

velopment. Staff development, sample materials and on-site followup visits were valued by educators. Educators preferred incremental improvements in their current curricula and instructional strategies rather than researchers providing structured curricula.

Improvements in current curricula were the approach of the NAP intervention. Educators were enthusiastic to learn and integrate new teaching strategies into their current areas of expertise. Innovative classroom physical activity strategies were also shared by educators, in particular in the learning areas of English and mathematics.

\section{Discussion}

Overall results have shown that a multi-component behavioural health intervention can improve learners' health behaviour and increase physical activity participation during formal instruction, lunch breaks and after school.

In the South African National Curriculum Statement, ${ }^{29}$ physical education is now incorporated into the learning area called life orientation. Physical education or physical development and movement are learning outcomes of life orientation depending on the grade. These learning outcomes play an imperative role in providing children with physical activity for at least $30-60$ minutes per week during school hours. However, this duration has not reached recommended standards of physical activity for children. ${ }^{12,15-17}$ Therefore additional measures of physical activity such as the NAP intervention is suggested to help achieve physical activity recommendations and create an awareness of healthy lifestyles.

A study ${ }^{30}$ in the USA investigated whether children would compensate for school days of restricted physical activity opportunities by increasing activity levels after school. Children did not compensate. Results showed that after-school activity levels following an active day were actually higher than after-school activities following an inactive school day. If children are restricted or denied physical activity during school hours due to curriculum and/or school structures that decrease or eliminate physical activity, it appears that they will not voluntarily catch up on these lost opportunities of physical activity. ${ }^{30}$ Hence it is suggested that interventions that encourage sustained increase in physical activity participation among learners need to be incorporated into the school curriculum.

Finally, the possibility of inaccurate questionnaire data cannot be neglected. Therefore it is necessary to note some limitations of this study. Firstly, questionnaires were based on self-reports. This method can result in problems like memory bias, comprehensibility and concentration problems. Secondly, a purposive sample for this study was not representative of all school children in KwaZulu-Natal, therefore generalisations cannot be made to Grade 6 learners in other areas or provinces or to other grades. Thirdly, only selected schools that had acquired Health-Promoting School status were part of the study. Fourthly, the lack of a control group reduces the interpretability of the fitness data.

In summary, this pilot study showed that by implementing a realistic and feasible intervention, physical activity participation of primary school learners can be increased during and after school.

Educators were trained to provide organised physical activity within the school curriculum as well as within the classroom. Such activities did not hamper or change the primary outcomes of the lesson but instead provided educators with incremental improvements and instructional teaching strategies including physical movement in various learning areas.

School and community programmes that promote regular participation in physical activity and optimal nutritional choices for 
children could be among the most effective strategies for reducing the public health burden of chronic diseases associated with sedentary lifestyles. Programmes that provide children with the knowledge, attitudes, behavioural skills and confidence to participate in physical activity may establish a lifelong commitment to an active lifestyle.

\section{Acknowledgement}

The KwaZulu-Natal Department of Health and Education is thanked for supporting this project. The researchers would also like to thank the school-health nurses and officials from the KwaZulu-Natal Department of Health who provided substantial support during the study, as well as all participants.

\section{REFERENCES}

1. Yusuf S, Reddy S, Ônpuu S. Global burden of cardiovascular diseases Part I: General considerations, the epidemiologic transition, risk factors, and impact of urbanization Circulation 2001;104:2746-2753.

2. Wild S, Roglic G, Green A, Sicree R, King H. Global prevalence of diabetes: estimates for the year 2000 and projections for 2030. Diabetes Care 2004;7:1047-1053.

3. World Health Organization, ed. Global strategy on diet, physical activity and health. Fifty-Seventh World Health Assembly; 200417 April. Geneva: World Health Organization.

4. Freedman D, Khan L, Mei Z, Dietz W, Srinivasan S, Berenson G. Relation of childhood height to obesity among adults: The Bogalusa Heart Study. Pediatrics 2002;109(2):e23.

5. Freedman D, Khan L, Serdula M, Dietz W, Srinivasan S, Berenson G. The relation of childhood BMI to adult adiposity: the Bogalusa Heart Study. Pediatrics 2005;1:22-7.

6. Armstrong M, Lambert M, Sharwood K, Lambert E. Obesity and overweight in South African primary school children - the Health of the Nation Study. S Afr Med J 2006;96:439-444.

7. Steyn N, Labadarios M, Maunder E, Nell J, Lombard C. Secondary anthropometric data analysis of the national food consumption survey in South Africa: The double burden. Nutrition 2005:4 -13.

8. Temple NJ, Steyn NP, Myburgh NG, Nel JH. Food items consumed by students attending schools in different socioeconomic areas in Cape Town, South Africa. Nutrition 2006;22:252-258.

9. McVeigh JA, Norris SA, Cameron N, Pettifor J. Associations between physical activity and bone mass in black and white South African children at age 9. J Appl Physiol 2004;97:1006-1012.

10. Tones K, Tilford S. Health promotion: effectiveness, efficiency and equity. London: Nelson Thornes; 2001.

11. Symons CW, Cinelli B, James TC, Groff P. Bridging student health risks and academic achievement through comprehensive school health programs. Journal of School Health 1997;67(6):220-227.

12. Sallis J, Patrick K. Physical activity guidelines for adolescents: consensus statement. Pediatric Exercise Science 1994;6:302-314.
13. Williams C, Hayman L, Daniels S, Robinson T, Steinberger J, Paridon C. Cardiovascular health in childhood: a statement for health professionals from the Committee on Atherosclerosis, Hypertension, and Obesity in the Young (AHOY) of the council on cardiovascular disease in the young, American Heart Association. Circulation 2002;106:143-160.

14. Stone E, McKenzie T, Welk G, Booth M. Effects of physical activity interventions in youth: Review and synthesis. Am J Prev Med 1998;15(4):298315.

15. Cavill N, Biddle S, Sallis J. Health enhancing physical activity for young people: statement of the United Kingdom Expert Consensus conference. Pediatric Exercise Science 2001;13:12-25.

16. Dietary Guidelines Advisory Committee. Dietary guidelines for Americans Washington, DC: US Dept of Health and Human Services and US Dept of Agriculture; 2000.

17. Corbin C, Pangrazi R. Physical activity for children: a statement of guidelines. Reston, Va: National Association for Sport and Physical Education; 1999.

18. McKenzie T, Sallis J, Faucette N, Roby J, Kolody B. Effects of a curriculum and inservice program on the quality of elementary physical education classes. Res Q Exerc Sport 1993;64(2):178-187.

19. Sallis J, McKenzie T. Physical educators role in public health. Res $Q$ Exerc Sport 1991;62:124-137.

20. Dwyer T, Coonan W, Leitch D, Hetzel B, Baghurst R. An investigation of the effects of daily physical activity on the health of primary school students in South Australia. Int J Epidemiol 1983;12:308-313.

21. Sallis J, McKenzie T, Kolody B, Lewis M, Marshall S, Rosengard P. Effects of health-related physical education on academic achievement: project SPARK. Res Q Exerc Sport 1999;70:127-134.

22. Shephard R, Volle M, Lavallee H, LaBarre R, Jequier J, Rajic M. Required physical activity and academic grades: a controlled study. In: IImarinen J, Valimaki I, eds. Children and sport. Berlin: Springer-Verlag; 1984. p. 58-63.

23. Sallis J, McKenzie T, Alcaraz J, McKenzie T, Hovell M. Predictors of change in children's physical activity over 20 months: variations by gender and level of adiposity. Am J Prev Med 1999;16:222-229.

24. Tomporowsi P. Cognitive and behavioral responses to acute exercise in youths: a review. Pediatric Exercise Science 2003;15:348-359.

25. Hardeman W, Griffin S, Johnston M, Kinmonth A, Wareham N. Interventions to prevent weight gain: a systematic review of psychological models and behaviour change methods. Int J Obes 2000;24:131-143.

26. Eurofit. Eurofit tests of physical fitness. 2nd ed. Strasbourg; 1993.

27. Pate P, Davis C, Robinson T, Stone E, McKenzie T, Young J. Promoting physical activity in children and youth: a leadership role for schools. Circulation 2006;114:1214-1224.

28. Preventing and managing the global epidemic of obesity. Report of the World Health Organization Consultation of Obesity. Geneva: WHO; 1997.

29. Department of Education. Revised National Curriculum Statement Grades R-9 (Schools). Life Orientation. Pretoria; 2002.

30. Dale D, Corbin C, Dale K. Restricting opportunities to be active during school time: Do children compensate by increasing physical activity levels after school? Res Q Exerc Sport 2000;71(3):240-248. 